\title{
Modern Educational Technology Ability Training Model for University Teachers
}

\author{
Feng LU \\ Northwestern Polytechnical University Xi'an, Shanxi Province, China \\ maoma00@163.com
}

Keywords: University Teachers; Modern Educational Technology; Ability Training; Model

\begin{abstract}
With the gradual advance of China's educational information process and vigorous development of modern educational technology, modern educational technology capability has become an important part of the professional quality of modern university teachers. Due to work-study conflicts, inadequate interaction and other defects, the traditional teacher training model is becoming increasingly unsuitable to new requirements over teachers proposed by the current era. In response to this current situation, this paper tries to integrate the popular online education model and flexible management concept into the training process of modern education technology ability training for university teachers, and thus forms a network-based flexible modern educational technology training model for university teachers. Through practice, it is found that the model can fully mobilize the teacher subjective initiative, and provide a new way of thinking for the development of the educational cause of teachers.
\end{abstract}

\section{Introduction}

With the gradual advance of China's educational information process and vigorous development of modern educational technology, modern educational technology capability has become an important part of the professional quality of modern university teachers.

\section{Current Situation of Modern Educational Technology Ability Training Model for University Teachers}

In the current situation, the modern education technology ability training for teachers is facing the following problems. The first problem is the conflict between more teaching content and less intensive training class hours. Modern educational technology has strong practice and rich contents, the teachers are required to master lots of technologies and skills very much. However, the university teachers have to complete a large number of daily works, do the class teaching is superficial and stereotyped within the limited training hours. The second problem is the conflict between more trainee teachers and less training teachers. At present, university teachers display inadequacies in educational technology more or less, yet there is relatively small number of teachers who engage in educational technology ability training, and the proportion is relatively unbalanced. The third problem lies in the conflict between orientation to teachers with different professions and training of discipline integration ability. Modern educational technology ability training is established for teachers who have training needs in different professions. Unified curriculum setting has ignored the differences of teacher application in varied professional fields. If the subject teaching is not associated, it will be difficult for teachers to truly experience the roles of modern educational technology in the subject teaching. The fourth problem lies in the conflict between single teaching forms and diverse ability training. The traditional classroom modern educational technology ability training focuses on teaching of teachers, and ignores the practical operation. It is difficult for the traditional training model to display the features of modern educational technology itself. 


\section{Presentation of Modern Educational Technology Ability Training Model for University Teachers}

According to current situation of modern educational technology training for teachers, on the one hand, this paper introduces online teaching in the teaching process, and builds an online training platform, in order to improve the conflicts between more contents and less hours as well as conflicts between single teaching forms; on the other hand, this paper introduces the flexible business management ideas in the network-based teaching process, in order to manage the network-based teaching process by using the advanced management concept in modern business management.

Online teacher training has the following advantages: the open network is favorable for teachers to learn independently, reduce the conflicts between works and learning; the convenient network helps to improve the efficiency of teacher training; the interactive network helps to enrich the teacher training methods. Flexible management was first derived from business management, which could also be called "human-based management". By introducing the flexible business management concept into the process of teacher training and focusing on the trainee teachers, the teachers can participate in modifying the program setting, training time, training method and training contents, which could fully mobilize the initiatives of teachers and get better training effects. The network-based flexible modern educational technology training model for teachers has convenient training form, rich training contents and flexible training time. At the same time, this paper introduces the idea of flexible management to regulate and control the whole process of training, and fully mobilizes the subjective initiative of teachers, which are expected to improve the efficiency of teacher training, and make contribution to promoting the development of teacher education cause.

\section{Establishment of Modern Educational Technology Ability Training Model for University Teachers}

\section{(I) Establishment of Online Training Platform}

Online modern educational technology training platform include four sub-platforms of the resource management platform, the learning process management platform, online exchange platform, management and evaluation platform as well as four back-end databases of the massive resource database, the learning process definition database, information exchange database, academic performance and achievement database.

1. Resource Management Platform. Resource management platform provides the management function for massive resource database. The massive resource database is jointly built by teachers and students, breaking the traditional, single model of teachers spreading knowledge to trainees. The trainee teachers transform the traditional passive acceptance of knowledge into actively sharing knowledge to other trainee teachers. In such a way, the information source of resource database becomes broader, and each platform user is able to make contribution to the establishment of massive resource database.

2. Learning Process Management Platform. This paper introduces the concept of learning flow in the learning process management platform. Learning flow is formalized representation of the learning process, describes the activities in the learning process as well as the most basic sequential order and flow relationships of each activity, which is used for the organization and management of learning activities as well as the result of learning process modeling. In this platform, the learning process flow definition is maintained by the professional training teacher and saved in the learning process definition database.

3. Online Exchange Platform. Online exchange platform provides real-time and non-real-time exchange ways, providing strong supports for the exchange between trainee teachers and professional training teachers. Among these, non-real-time exchanged information is saved in the exchange information database, in order to facilitate users in other platforms to view.

4. Management and Evaluation Platform. Management and evaluation platform can automatically record the learning process into the academic performance and achievement database, real-time 
track the learning progress of trainee teachers, and provide a strong basis for the latter evaluation and assessment of the professional training teachers.

\section{(II) Implementation Strategies for Flexible Training Management}

1. Flexible Training Organization Form. The so-called flexible training organization form refers to break the limit of traditional teacher training, according to the development requirements of the school and the professional development requirements of teachers, consciously, keep pace with the times, and flexibly and continuously carry out training for teachers in limitless network. First of all, the place for teachers to receive training is flexible, so that the trainee teachers can flexibly select the place for training according to their actual situation; Secondly, the time for teachers to receive training can be freely arranged, which has solved the work-study conflict existed in traditional teacher training model; thirdly, the system will recommend appropriate teaching resources according to the conditions of trainee teachers, on this basis, the trainee teachers will freely choose to browse the content they are interested in according to their own needs, which has solve the defect of trainee teachers failure to freely choose training contents in the traditional training; Finally, the trainee teachers can exchange their training experience with other teachers through the network, which has changed the deflect of traditional training model's inadequate interaction.

2. Flexible Training Contents. In the flexible network-based modern educational technology ability training model, the training contents are real-time updated. The network-based teacher training can make full use of existing network resources, break the temporal and spatial limits, and convey the latest education philosophy and new educational technology to the trainee teachers, so that the teachers can keep pace with the knowledge economy, find their problems existed in the teaching process, and grasp the latest and most practical job skills at first time. While keeping the training contents real-time updated, the teachers can also inherit previous knowledge system, and build the comprehensive knowledge system views. The trainee teachers can also participate in formulating the training program, provide optional training contents for training organizers, and enrich the resources of online training platform. Therefore, by using the flexible network-based teacher training, the training contents are not single any more, but instead, they are diverse, dynamic and continuously developed.

3. Flexible Training Process Management. Online education is a teaching model that highlights "learning" over "teaching", and the learning initiative is mastered by the trainees. Therefore, if there is inadequate organization and management in the learning process, it will be hard to ensure the learning effect. Management of learning process has the following advantages: promote the learning progress according to the learning conditions of trainee teachers, control the delivery order and time of learning resources, appropriately allocate the learning tasks, achieve the request of "conveying the most suitable works at the most appropriate time", automatically adapt to the learning abilities of trainee teacher individuals; produce and manage a process instance for each trainee teachers, support flexible learning path management, in order to realize individualized education; the trainee teachers can seek the best learning partner in the learning process for mutual exchange and discussion, in order to facilitate cooperative learning and team learning; this platform can integrate with various learning tools and provide comprehensive supports for online learning; be able to conduct strict management and monitoring towards the learning process, record and reflect the completion conditions of each node.

4. Flexible Training Evaluation System. Most of the traditional teacher training evaluations are completed through exams, which evaluate the training effects through grade levels. However, the evaluation system cannot reflect the process of trainee participating in the training. In the flexible network-based modern educational technology ability training model, the learning process can be automatically recorded in the academic performance and achievement database through the management and evaluation platform, in order to real-time track the learning progress of trainee teachers, combine the qualitative evaluation with quantitative evaluation, and build a training evaluation system aiming at promoting the personality development of teachers. Online information collection can be comprehensive and timely, and the online monitoring system can real-time track 
the online learning activities of trainee teachers. By recording the trainee teacher's active degree in the online teaching platform and recording the active degree of trainee participation in online learning, this paper gives a relatively integrated, comprehensive, and objective training evaluation.

\section{Conclusion}

Any training model is not perfect, so does the network-based training model. In the traditional training, the interpersonal emotional communication, interaction between teachers and students in teaching and the practical teaching methods cannot be replaced by network-based training. Therefore, the network training shall have mutually combined and mutually complemented relationship with the traditional training. The development of two training models are not mutually replaceable, instead, they should be mutually penetrated, complemented and jointly developed. The network-based teacher training and traditional teacher training can be divided in labor and overlap each other from the aspect of training level and training goal.

\section{References}

[1] Peng Yaqing. Exploration of Network-based Teacher Training Strategies [J]. The Inservice Education and Training of School Teachers, 2007 (4).

[2] Zhu Yan. e-Learning: Exploration of Teacher Training Model at the Internet Age [J]. Adult Education, 2006 (7).

[3] Cao Meiqin. Flexible Management - New Concept of Library Management [J]. Academic Library and Information Service, 2006 (3).

[4] Yu Xuying. Development of Flexible Management and Its Ideological Cultural Origins [J]. Economist, 1998 (1). 